\title{
Increasing cataract surgery to meet Vision 2020 targets; experience from two rural programmes in east Africa
}

\author{
S Lewallen, H Roberts, A Hall, R Onyange, M Temba, J Banzi, P Courtright
}

Br J Ophthalmol 2005;89:1237-1240. doi: 10.1136/bjo.2005.068791

See end of article for authors' affiliations

.....................

Correspondence to: Susan Lewallen,

Kilimanjaro Centre for Community

Ophthalmology, Tumaini

University/KCM College,

PO Box 2254, Moshi,

Tanzania; slewallen@kcco.

net

Accepted for publication 1 May 2005
Background: The numbers of cataract surgeries done in sub-Saharan Africa fall short of Vision 2020 targets. Over a few years, two programmes in rural east Africa both achieved significant increases in the number of cataract surgeries they provide, resulting in cataract surgical rates of 1583 for Kwale District in Kenya and 1165 for Kilimanjaro Region in Tanzania. Key components of success in these two programmes are described.

Methods: Data were collected on standard indicators and key personnel interviewed to describe the results and compare the methods employed to increase cataract surgical rates by the Kwale District Eye Centre programme and the Kilimanjaro regional Vision 2020 programme.

Results: Key components of success shared by the programmes included: (1) programmes in the community and at the hospital are closely linked so that they increase capacity together; (2) community programmes are "patient friendly," providing service in one stop; (3) the examination team includes eye workers with enough skill to provide treatment and decide who is operable so that patients are not transported needlessly or sent through a lengthy referral chain; (4) sites for visits in the community are selected according to population distribution and they are visited according to a regular schedule.

Conclusion: The development of "bridging strategies" that create a strong link between hospitals providing clinical service and communities needing these services is a key component to realising Vision 2020 goals in sub-Saharan Africa.
B lindness affects approximately six million people in Africa, ${ }^{1}$ with cataract accounting for about half of this number. The reasons for the large burden of cataract blindness have been documented; the barriers to use of services are both provider based and community based..$^{2-5}$ Africa's persistent high prevalence of cataract related blindness and generally low output by service providers was one stimulus for the creation of Vision 2020, a global initiative to eliminate avoidable blindness by the year $2020{ }^{6}$

The Vision 2020 initiative recommends that planning, implementation, and monitoring of blindness prevention programmes should occur within geopolitical administrative "districts" of approximately one million population (sometimes called "regions"). Planning at this level for service delivery is critical to making Vision 2020 work on a global scale. Targets for the number of cataracts requiring operation per million population per year (the cataract surgical rate, or CSR) in order to eliminate avoidable blindness by the year 2020 vary globally from 2000-5000. Currently, the CSR in most sub-Saharan countries remains less than 500. ${ }^{7}$ In 2002 the CSR in Tanzania was 313 and in Kenya it was estimated at 644 . Within both countries there are large variations in CSR by region; in some regions the CSR has been raised significantly as a result of specifically planned programmes, but there is little documentation of the features of these programmes. We studied two regional plans, both of which have resulted in significant increases in the number of cataracts operated in their catchment areas, to document key components of success in their programmes

\section{METHODS}

We collected sociodemographic data from governmental and international agencies on the populations served. Data on service delivery for the years 1998 to 2004 came from hospital management reports. We used the questionnaire, "Baseline data on facility," as a guide to interview key personnel and collect information on the hospitals (Quality Cataract Series: Financial Sustainability, pp 43-56, published by Aravind Eye Hospitals and Postgraduate Institute of Ophthalmology, Lions Aravind Institute of Community Ophthalmology (India) and Seva Foundation, USA, February 2001).

\section{RESULTS}

Characteristics of hospitals and populations served Kwale District (population 600000) is located in southeast Kenya. The population, primarily Muslim from the Digo and Nduruma tribes, is rural, with no population centres over 50000 people. Most people earn their living from subsistence farming and fishing; the district is considered one of the poorer in Kenya. The Kwale District Eye Centre programme (KDEC), comprising both hospital and outreach programmes, is the major eye care service provider for Kwale District. There is one Ministry of Health eye care worker stationed in the district (not trained in cataract surgery) as well as occasional service provided by outreach visits from Mombassa.

Kilimanjaro Region (population 1.4 million) in northern Tanzania comprises six districts with populations from 175000 to 300000 . There are three main ethnic groups: the Chagga on the slopes of Mt Kilimanjaro, the Masai on the dry steppe, and the Pare in the southern areas. The population is primarily rural, most living as subsistence farmers or herdsmen. The region ranks in the middle of the economic profile of the country. Eye services in the region are provided predominantly through the Kilimanjaro Regional Vision 2020 programme. This programme is built around surgical services at the Kilimanjaro Christian Medical Centre (KCMC) Eye Department in Moshi supported by a community outreach programme including the Ministry of Health, the Kilimanjaro

Abbreviations: CSR, cataract surgical rate; $\mathrm{KCCO}$, Kilimanjaro Centre for Community Ophthalmology; KDEC, Kwale District Eye Centre programme; KCMC, Kilimanjaro Christian Medical Centre 
Table 1 Populations served by the hospitals/programmes

\begin{tabular}{lll}
\hline & Kwale District & Kilimanjaro Region \\
\hline Population & 600000 & 1400000 \\
Distance $\left(\mathrm{km}^{2}\right)$ covered & 8600 & 13309 \\
Population density $\left(\mathrm{km}^{2}\right)$ & 69.8 & 105.2 \\
Gross national income (US\$) & 360 (Kenya overall) & 280 (Tanzania overall) \\
$\%$ population below food poverty line & $58 \dagger$ & $11 \ddagger$ \\
$\%$ household expenditure used for food & 63.5 & 70 \\
Literacy rate & $45.6 \% \S$ & $85 \ddagger$ \\
\hline \multirow{2}{*}{ *2002, for Kenya and Tanzania as countries (World Bank). } & \\
†Ministry of Finance and Planning, Second report on poverty in Kenya 2000;vol 1:p31. \\
†Household Budget Survey Tanzania 2001 final report (available at www.tanzania.go.tz/statistics.html). \\
\$Ministry of Finance and Planning, Second report on poverty in Kenya 2000;vol 2:p46 (literacy).
\end{tabular}

Centre for Community Ophthalmology (KCCO), the Community Based Rehabilitation Programme of Kilimanjaro, and local Lions clubs.

In both Kilimanjaro and Kwale, cataract is estimated to account for $50 \%$ of blindness; trachoma exists in both areas although it probably accounts for less than $5 \%$ of blindness. Other descriptive indicators of the populations and the hospital services are shown in tables $1-3$.

The changes in the numbers of total cataract surgeries provided are shown in figure 1. Strategies to achieve the CSRs in table 3 included changes in the community programmes and at the hospitals.

\section{Characteristics of new community based programmes} Community programmes existed in Kwale District and Kilimanjaro Region since the mid-1990s but the numbers of patients recruited for cataract surgery were still low. Prompted by the recognition that Vision 2020 targets were not being met, both centres initiated new community programmes (1998 in Kwale and 2002 in Kilimanjaro). In Kwale, the programme is coordinated by KDEC and in Kilimanjaro it is coordinated by the KCCO.

The new community programmes share many features that may be important in success (table 4 ). The fixed sites for team visits are selected based on population centres and density. (In Kilimanjaro the regional and district Ministry of Health are responsible for deciding the placement of the sites.) The teams are organised and directed by trained managers and include one or more examiners, nurses, and field assistants. The Kilimanjaro examiners are ophthalmologists, residents, and assistant medical officers from the KCMC Eye Department and the Ministry of Health; Kwale uses its own trained nurses as examiners. The Kilimanjaro team includes an optometrist and the Kwale programme includes low vision services.

Patients are provided with transport to hospital on the day of diagnosis, receive surgery the following day, and are provided with transport back to the site 1-2 days later. Both hospitals use a combination of hospital vehicles (minibus or four wheel drive passenger cars) and public buses to transport patients. Follow up care is provided by field workers in Kwale and by district eye coordinators (Ministry of Health) in Kilimanjaro.

In Kwale, 12 full time field workers who live in the community advertise upcoming team visits and conduct periodic eye health education with community groups and schools. In Kilimanjaro, upcoming team visits are advertised a week ahead by radio, posters, and visits to key leaders, and are carried out by district Ministry of Health and KCCO staff. In Kilimanjaro, patients are registered and pay 15000 Tsh (about $f 8$ ) in the field. In Kwale most patients do not pay anything, although some make a contribution upon reaching the hospital. Cataract surgical uptake is shown in table 5.

\section{Changes required at the hospitals}

Both hospitals had well trained ophthalmologists offering ECCE with IOL as the standard treatment. However, both had to change to accommodate an increased number of patients.

The significant changes at KCMC eye department included:

- A new computerised registration system for the eye department allowed large number of patients to be admitted quickly and "after hours."

- The recording of vital signs, consent for surgery, and collection of surgical fees in the field made admission into the ward faster. Simpler nursing forms for cataract patients reduced paperwork.

- Instead of levying separate charges (for example, for surgery, IOL, bed fee, medicine) the price for cataract surgery was "packaged" in one fee.

- The introduction of locally made camp beds increased the number of hospital "beds," allowing existing space to be used efficiently and requiring less nursing maintenance.

Table 2 Characteristics of the hospitals

\begin{tabular}{lll}
\hline & KDEC Hospital & KCMC Eye Department \\
\hline Scope of services & $\begin{array}{l}90 \% \text { of surgery is cataract and } \\
\text { trabeculectomy. No general } \\
\text { anaesthesia available }\end{array}$ & $\begin{array}{l}\text { Eye department provides full services including } \\
\text { paediatric, vitreoretinal, and oculoplastic services }\end{array}$ \\
$\begin{array}{l}\text { In-house training for KDEC staff } \\
\text { (including cataract surgeon) }\end{array}$ & $\begin{array}{l}\text { National tertiary training centre: enrols } 3 \text { cataract } \\
\text { surgeons each year for 2 year training and 2-3 } \\
\text { ophthalmology residents each year for } 4 \text { year } \\
\text { training }\end{array}$ \\
Governance & $\begin{array}{l}\text { This is an autonomous eye hospital } \\
\text { that sets it own personnel policies } \\
\text { and determines staff positions }\end{array}$ & $\begin{array}{l}\text { The eye department exists within a large tertiary } \\
\text { multispecialty referral hospital. Personnel policies } \\
\text { and staff positions are subject to approval by } \\
\text { central hospital }\end{array}$ \\
\hline
\end{tabular}


Table 3 Cataract services in 2004

\begin{tabular}{lllc}
\hline & & $\begin{array}{l}\text { Kwale } \\
\text { District }\end{array}$ & $\begin{array}{l}\text { Kilimanjaro } \\
\text { Region }\end{array}$ \\
\hline A & $\begin{array}{l}\text { Total number of age related cataracts operated by } \\
\text { main service provider } \\
\text { \% of patients (A) coming from defined catchment } \\
\text { area (Kwale District or Kilimanjaro Region) }\end{array}$ & 1508 & 1868 \\
B & $\begin{array}{l}\text { Number of cataracts operated on patients from } \\
\text { catchment area by other service providers }\end{array}$ & 30 & 146 \\
C & 1583 & 1165 \\
$\begin{array}{l}\text { Cataract surgical rate } \\
(\mathrm{B} \times \mathrm{A})+\mathrm{C}) / \text { population) }\end{array}$ & & \\
\hline
\end{tabular}

- The productivity of surgeons was increased by introducing two tables per senior surgeon, more standardisation of surgical techniques, and increased emphasis on punctuality for all staff.

The significant changes in the Kwale Hospital to allow service to more patients included:

- A new building was constructed with more ward and theatre space.

- One paramedical cataract surgeon was hired to join the ophthalmologist.

- One new ophthalmic nurse/technician was hired and trained to examine and diagnose most eye diseases.

- Salaried full time community based workers were recruited to replace volunteers (who had been paid per numbers of patients they produced).

\section{DISCUSSION}

For a variety of reasons, most people needing cataract surgery in sub-Saharan Africa do not present on their own to hospitals, even when high quality, affordable services are available. ${ }^{8}$ Although the two hospitals/programmes described here are very different in some ways, the populations they serve are similar and both achieved significant increases in the numbers of surgeries they perform and in their CSR. The key to this was long range planning and implementation of programmes designed (1) to overcome the barriers at the community level preventing patients from using the service, and (2) to make specific changes at the hospital essential to providing more service.

The community programmes developed independently of each other although both are based on the "Aravind model." They share a number of important characteristics: both are designed to avoid the time consuming and often frustrating "referral chain" characteristic of many primary healthcare systems. Our experience with the traditional "screening model" in which low level eye care workers identify patients

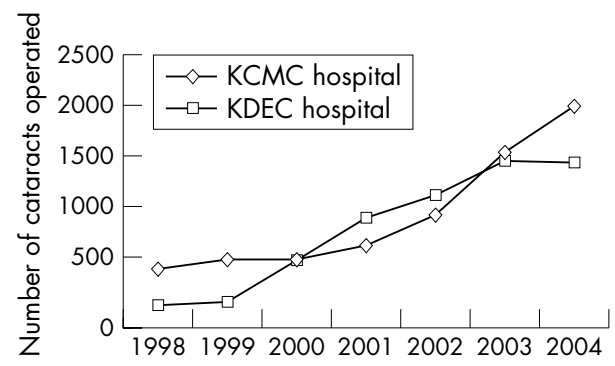

Figure 1 Change in the total number of cataracts operated at the hospitals over time. (The KCMC numbers include adult and childhood cataracts.) with visual impairment and refer them on for more definitive care is that very few patients follow that advice. Furthermore, because their diagnostic skills are limited, these health workers may turn away all but the most advanced cataract patients and refer irreversibly blind patients for surgery, resulting in inconvenience and disappointment.

The hospitals are different in terms of scope of services and governance. KDEC was relatively new, and under dynamic leadership since its inception. It had a productive and skilled staff and needed primarily to increase the number of staff and the space. KCMC Eye Department had ample space, but a large entrenched workforce working below capacity. It needed to increase productivity and skills of existing staff.

Neither programme operates in isolation. Just outside Kwale District, service organisations and other hospitals occasionally run "clinics" in which they take Kwale District patients outside the district for free surgery. This makes it difficult for KDEC to encourage people who have the capacity to pay for surgery to agree to do so. In our experience in eastern Africa, "waiting for free surgery," is frequently offered as the reason for enduring years of cataract blindness. This was also documented in Nepal. ${ }^{9}$

Both programmes rely on programme managers who have the authority to make high level decisions. Clinicians are part of the teams in the field and at the hospitals, but they are not expected to run the programmes. Both programmes have benefited from advice on management and programme development as well as financial support from a range of national and expatriate partners. Such support can be helpful in driving or changing policy. The strong partnership with the regional and district level Ministry of Health was critical in discouraging old style free ICCE (intracapsular cataract extraction) camps, engaging local service clubs, and planning all aspects of the programme (including site selection) in Kilimanjaro Region.

Around $30 \%$ of cataract patients in Kwale do not accept surgery, in spite of the fact that they do not have to pay for it. In Kilimanjaro, the majority of the patients pay the full fee after counselling. There is a mechanism in place to serve those who cannot pay, but this is not mentioned in advertising and it is possible that some patients without 15000 Tsh simply do not come to the Kilimanjaro sites. We also note that the proportion of patients with operable cataract who attend sites in Kwale is about twice that in Kilimanjaro (table 5). A better understanding of these differences could help us modify the programmes to serve more patients.

These programmes serve populations that share socioeconomic and demographic similarities with many others in sub-Saharan Africa and it may be that these experiences are relevant elsewhere. In Malawi, for example, a large increase in cataract patients was achieved with an outreach programme sharing many of the features described here and closely coordinated with changes in the hospital service (International Eye Foundation, personal communication). 
Table 4 Key similarities in the two community programmes

Factor Advantage

Decision to do surgery made on site

Patient avoids several trips through referral system

Examiner at site has enough training to differentiate causes of visual impairment

Allows accurate counselling in the field and avoids

Patient transported to hospital the same day as diagnosis transporting patients with inoperable diseases

Patients transported to and from hospital

Takes advantage of presumed willingness to act at the time

Overcomes a number of barriers including cost of transport, reluctance to make journey to unfamiliar place, need for patient to bring a companion

Team includes a dedicated counsellor Patient and family have a chance for questions to be answered at length by non-threatening personnel

No hidden charges (packaged deal)

Patients know exactly how much they will pay for round trip transport, food, accommodation, surgery with $\mathrm{IOL}$, preoperative and postoperative medicines, and follow up

No fee for examination at site Encourages patients to attend

Fixed sites are visited regularly and never cancelled once advertisement has gone out

Community and patients develop trust in the service

Community programmes are closely coordinated with hospital services

Hospitals are aware of and can plan to cope with periodic influxes of patients

Table 5 Service and uptake of cataract surgery in community in 2004

\begin{tabular}{lll}
\hline & $\begin{array}{l}\text { KDEC (for Kwale } \\
\text { District only) }\end{array}$ & $\begin{array}{l}\text { Kilimanjaro (for Kilimanjaro } \\
\text { Region only) }\end{array}$ \\
\hline Number of people screened and treated & 10389 & 14093 \\
Number of people recommended for surgery & 1180 & 816 \\
Number of people who accept surgery (uptake) & $814(68.9 \%)$ & $675(82.7 \%)$ \\
\hline
\end{tabular}

The sustainability of eye care delivery programmes is important and depends on both organisational and financial systems being strong enough to weather changes in leadership, staff, socioeconomics, political factors, and donor vagaries. A programme's ability to generate funds to meet its expenses contributes to long term financial sustainability. Both of these programmes currently use a combination of donor funds and patient revenues to meet their expenses but a useful analysis of their cost recovery is beyond the scope of this paper.

Mobilising patients for surgery by the methods described here is more expensive to the healthcare system than if they came on their own. We hope to increase demand by building awareness and confidence in the quality of services. Meanwhile, as more descriptions of programmes that successfully increase the CSR emerge, we can begin to analyse the factors that are common to success and the financial implications of the methods used.

\section{ACKNOWLEDGEMENTS}

This study was supported by the International Eye Foundation. KDEC, KCMC Eye Department, and KCCO are all supported by numerous donors to whom we are grateful. The community outreach programmes described here are supported by Christoffel Blindenmission, Seva Foundation, Seva Canada, and SightSavers International. Ms Claudette Hall assisted in compiling information on the community programmes.

\section{Authors' affiliations}

S Lewallen, J Banzi, P Courtright, Kilimanjaro Centre for Community Ophthalmology, Tumaini University/KCM College, PO Box 2254, Moshi, Tanzania

H Roberts, R Onyange, Kwale District Eye Centre, Kwale, Kenya A Hall, Kilimanjaro Christian Medical College, Eye Department, PO Box 3010, Moshi, Tanzania

M Temba, Ministry of Health, Kilimanjaro Region, PO Box 3054, Moshi, Tanzania

\section{REFERENCES}

1 Resnikoff S, Pascolini D, Etya'ale D, et al. Global data on visual impairment in the year 2002. Bull World Health Organ 2004;82:844-51.

2 Courtright P, Kanjaloti S, Lewallen S. Barriers to acceptance of cataract surgery among patients presenting to district hospitals in rural Malawi. Tropical and Geographic Medicine 1995:47:15-18.

3 Melese M, Alemayehu W, Friedlander E, et al. Indirect costs associated with accessing eye care services as a barrier to service use in Ethiopia. Trop Med Int Health 2004;9:426-31.

4 Rotchford AP, Rotchford KM, Mthethwa LP, et al. Reasons for poor cataract surgery uptake - a qualitative study in rural South Africa. Trop Med Int Health 2002;7:288-92.

5 Johnson GJ, Goode V, Faal H. Barriers to the uptake of cataract surgery. Trop Doctor 1998:28:218-20.

6 Lewallen S, Courtright P. Blindness in Africa: present situation and future needs. Br J Ophthalmol 2001;85:897-903.

7 Foster A. Cataract and "Vision 2020-the right to sight" initiative. Br J Ophthalmol 2001;85:635-7.

8 Eloff J, Foster A. Cataract surgical coverage: results of a population-based survey at Nkhoma, Malawi. Ophthalmic Epidemiol 2000;7:219-21.

9 Shrestha MK, Thakur J, Gurung CK, et al. Willingness to pay for cataract surgery in Kathmandu Valley. Br J Ophthalmol 2004;88:319-20. 